T. Costacou $\cdot$ J. C. Zgibor $\cdot$ R. W. Evans $\cdot$ J. Otvos $\cdot$

M. F. Lopes-Virella • R. P. Tracy • T. J. Orchard

\title{
The prospective association between adiponectin and coronary artery disease among individuals with type 1 diabetes. The Pittsburgh Epidemiology of Diabetes Complications Study
}

Received: 28 January 2004 / Accepted: 13 July 2004 / Published online: 23 December 2004

C) Springer-Verlag 2004

\begin{abstract}
Aims/hypothesis: Recent findings suggest the potential involvement of adiponectin in obesity, diabetes and cardiovascular disease. We assessed the prospective association between adiponectin concentration and coronary artery disease in individuals with type 1 diabetes. Methods: Participants were identified from the Pittsburgh Epidemiology of Diabetes Complications cohort, a prospective follow-up study of childhood-onset type 1 diabetes. At baseline, subjects had a mean age of 28 years, and a mean diabetes duration of 19 years. Cases (deter mined by physician-diagnosed angina, confirmed myocardial infraction, stenosis $\geq 50 \%$, ischemic ECG or revascularization) were matched to the control subjects with respect to sex, age and diabetes duration. Samples and risk factors for analyses were identified from the earliest exam prior to incidence in cases. Sera and information on all covariates were available for 28 cases and 34 control subjects. Proportional hazards models were constructed including matching variables. Results: Compared with
\end{abstract}

T. Costacou - J. C. Zgibor - R. W. Evans · T. J. Orchard Department of Epidemiology, Graduate School of Public Health, University of Pittsburgh,

Pittsburgh, PA, USA

J. Otvos

LipoScience,

Raleigh, NC, USA

M. F. Lopes-Virella

Department of Medicine, Medical University of South Carolina,

Charleston, SC, USA

R. P. Tracy

Laboratory for Clinical Biochemistry Research, University of

Vermont,

Colchester, VT, USA

T. J. Orchard $(\bowtie)$

Diabetes and Lipid Research Building, 3512 Fifth Avenue,

Pittsburgh, PA, 15213, USA

e-mail: tjo@pitt.edu

Tel.: +1-412-3831032

Fax: $+1-412-3831020$ those in men, adiponectin concentrations were elevated in females $(p=0.009)$ and among individuals with macroalbuminuria $(p=0.04)$. In multivariable analyses (adjusting for standard risk factors as well as lipoprotein measurements determined by nuclear magnetic resonance spectroscopy, E-selectin or antioxidants), adiponectin inversely predicted the incidence of coronary artery disease (hazard ratio $=0.37$ per 1 SD increase, 95\% CI $0.19-0.73$, $p=0.004)$. Conclusions/interpretation: The results suggest that increased adiponectin concentration is prospectively associated with a lower risk of coronary artery disease type 1 diabetes. The potential of adiponectin determination as a useful marker of, and potential therapeutic target for, coronary artery disease prevention in type 1 diabetes should be further explored.

Keywords Adiponectin · Coronary artery disease - Type 1 diabetes

Abbreviations CAD: coronary artery disease $\cdot$ EDC: the Pittsburgh Epidemiology of Diabetes Complications Study - eGDR: estimated glucose disposal rate $\cdot$ E-selectin: endothelial-leukocyte adhesion molecule-1 - HR: hazard ratio - ICAM-1: intercellular adhesion molecule-1 - MI: myocardial infarction

\section{Introduction}

Adiponectin is an adipose tissue-specific protein of the collectin family [1]. It is one of the most abundant circulating proteins in human plasma, with levels typically ranging from 5 to $30 \mu \mathrm{g} / \mathrm{ml}$, and accounts for $0.01 \%$ of total plasma protein [2]. Adiponectin preferentially accumulates in the subintimal space of the arterial wall when the vascular endothelium is injured [3] and inhibits TNF- $\alpha$-induced cell adhesion in human aortic endothelial cells and expression of vascular cell adhesion molecule-1 (VCAM-1), endothelial-leucocyte adhesion molecule-1 (E-selectin) and intercellular adhesion molecule-1 (ICAM1) in a dose-response manner [4]. It has also been shown 
to suppress the differentiation of myeloid progenitor cells, and inhibit TNF- $\alpha$ production, phagocytic activity and foam cell formation in mature macrophages [5]. These properties suggest that adiponectin may act as both an anti-atherogenic and an anti-inflammatory molecule.

Although the biological activities of adiponectin are not well understood, recent findings suggest its potential involvement in obesity, diabetes and cardiovascular disease. Indeed, one of the two identified quantitative trait loci that influence the phenotypes of the insulin resistance (metabolic) syndrome is located on chromosome 3q27, where the adiponectin gene is encoded [6]. Adiponectin administration has been shown to reverse insulin resistance and reduce triglyceride accumulation in the skeletal muscle and liver of lipoatrophic and obese rodent models by enhancing fatty acid combustion and energy dissipation in skeletal muscle [7]. Furthermore, the generation of adiponectin-deficient mice provided the first in vivo evidence that adiponectin is required for normal regulation of insulin sensitivity and glucose homeostasis, and that it protects against neointimal formation [8]. Adiponectinnull mice with normal glucose and lipid metabolism showed profound neointimal hyperplasia in mechanically injured arteries, indicating that injury-induced neointimal formation is directly caused by adiponectin deficiency and does not result from abnormalities in glucose and lipid metabolism [9]. In humans, low circulating levels of adiponectin have been associated with obesity [2, 10], severity of insulin resistance [10], glucose intolerance [10, $11]$ and coronary artery disease (CAD) [11]. Independently of diabetes, plasma adiponectin levels inversely predicted cardiovascular outcomes in patients with endstage renal disease and were related to metabolic risk factors such as insulin levels, insulin sensitivity, and triglyceride and HDL cholesterol levels [12]. In recent reports from the Pittsburgh Epidemiology of Diabetes Complications Study (EDC), both insulin resistance and markers of inflammation were important predictors of CAD in type 1 diabetes [13]. Based on these observations, the role of adiponectin as a key underlying factor linking these two causal pathways deserves further investigation.

The majority of studies that have examined adiponectin levels among individuals with diabetes mellitus have focused on type 2 diabetes [10,11, 14-16]. In the present study we aimed to assess adiponectin concentrations in individuals with type 1 diabetes mellitus in a case-control setting to determine whether adiponectin levels are reduced among patients who subsequently develop CAD, and whether adiponectin independently predicts future CAD events.

\section{Subjects and methods}

The Pittsburgh Epidemiology of Diabetes Complications Study

Participants were identified from the cohort used in the EDC, a 10-year prospective follow-up study of childhood onset ( $<17$ years of age) type 1 diabetes mellitus. Subjects were first seen between 1986 and1988, and were reexamined biennially over a 10 -year period. The EDC has been described earlier in detail [17, 18]. Briefly, study participants were diagnosed between 1950 and 1980, and seen within 1 year of diagnosis at the Children's Hospital of Pittsburgh (Pennsylvania, USA). Although this population is clinic based, it has been shown to be representative of the type 1 diabetes population of Allegheny County, PA [19]. Prior to their scheduled clinic visit, participants were sent questionnaires concerning demographic, healthcare, selfcare and medical history information. This analysis employed a nested case-control design that examined the relationship between new cardiovascular risk markers (not originally measured) and the incidence of diabetesassociated complications during the 10-year EDC followup period using stored samples.

Selection of cases and control subjects

Cases were defined as participants who developed CAD determined by angina diagnosed by an EDC physician or myocardial infarction (MI) confirmed by Q-waves on ECG or hospital records (Minnesota codes 1.1 or 1.2), or angiographic stenosis $\geq 50 \%$, coronary artery bypass surgery, angioplasty or ischemic ECG changes (Minnesota codes $1.3,4.1,4.3,5.1,5.3,7.1)$ during the follow-up period of the EDC. Cases were matched to control subjects without CAD in terms of gender, age and diabetes duration ( \pm 3 years). For cases and their matched control subject, samples were identified from the earliest examination prior to the incident event in the case for which samples were available (samples were drawn 6-116 months prior to the CAD event in the cases). ECD risk factors (i.e., BMI, hypertension, etc.) used in the statistical analyses were also selected from the same examination period (same year) as the sample (serum, and thus measurements of adiponectin, etc.). Sera and complete information on all covariates were available for 28 cases and 34 control subjects and were used in these analyses. Due to the small number of subjects with available serum samples for adiponectin measurements, unpaired analyses were performed, and matching variables were included in all models. No differences were observed between the CAD cases used in the analyses and those lacking adiponectin measurements $(n=69)$, with the exception of homocysteine levels, which were lower in the cases used. The University of Pittsburgh Institutional Board approved the study protocol.

Definition and assessment of EDC complications and risk factors

Measurements As mentioned above, EDC participants completed a questionnaire concerning demographic and medical history information before attending the clinic. An ever smoker was defined as a person who had smoked 
$\geq 100$ cigarettes over their lifetime. Blood pressure was measured with a random-zero sphygmomanometer according to the Hypertension Detection and Follow-up Program protocol after a 5-min rest [20]. Hypertension was defined as a systolic blood pressure $\geq 140 \mathrm{~mm} \mathrm{Hg}$, a diastolic blood pressure $\geq 90 \mathrm{~mm} \mathrm{Hg}$, or use of antihypertensive medication. Depressive symptomatology was assessed using the Beck Depression Inventory [21].

Laboratory measurements Stable glycosylated haemoglobin $\left(\mathrm{HbA}_{1}\right)$ was measured by ion-exchange chromatography (Isolab, Akron, OH, USA) and by automated HPLC (Diamat, BioRad, Hercules, CA, USA). Readings obtained using the two methods are almost identical $(r=0.95)$. HDL cholesterol was determined by a precipitation technique (heparin and manganese chloride) using a modified version [22] of the Lipid Research Clinics method [23]. Total cholesterol and triglycerides were measured enzymatically $[24,25]$. LDL cholesterol levels were calculated from measurements of the levels of total cholesterol, triglycerides and HDL cholesterol using the Friedewald equation [26].

Estimated glucose disposal rate (eGDR), a measure of insulin sensitivity, was estimated by a regression equation derived from hyperinsulinaemic-euglycaemic clamp studies on 24 subjects chosen to represent the full spectrum of insulin resistance in terms of associated risk factors [27]. White blood cell counts were obtained with a Coulter Counter (model S-plus IV, Beckman-Coulter, Fullerton, CA, USA) and fibrinogen using a biuret colorimetric procedure and a clotting method. C-reactive protein was measured by a colorimetric competitive ELISA [28]. Homocysteine was measured in duplicate using a commercial enzyme immunoassay kit (Bio-Rad). The interassay CV was $7.7 \pm 5.5 \%$ [20]. Because this procedure involves a reducing step, the method does not distinguish between homocysteine and its oxidised analogues. Adiponectin was measured using a RIA procedure developed by Linco Research. Briefly, samples were diluted 1:500 in assay buffer, mixed with ${ }^{125}$ I-adiponectin and anti-adiponectin antibody, and then incubated at room temperature for 20-24 h. The adiponectin-antibody complex was precipitated with precipitating agent at $4{ }^{\circ} \mathrm{C}$ for $20 \mathrm{~min}$, and then sedimented by centrifugation at $3000 \times \mathrm{g}$ for $20 \mathrm{~min}$. Finally, the supernatant was decanted and the pellets counted. Under these conditions, the limit of sensitivity is $1 \mathrm{ng} / \mathrm{ml}$ and the response is linear up to $200 \mathrm{ng} / \mathrm{ml}$. Standards, blanks, quality control and a control pool were run simultaneously with all samples. The CV between runs was $8.0 \%$.

Measurement of $\alpha$-tocopherol was performed as described by Driskell et al. [29] and Miller et al. [30]. All procedures were performed under subdued lighting. Aliquots $(500 \mu \mathrm{l})$ of serum were mixed with $500 \mu \mathrm{l}$ extractant and the samples shaken vigorously (vortexed for $10 \mathrm{~min}$ ) with $6 \mathrm{ml}$ petroleum ether. Supernatants were collected following centrifugation of the samples at $800 \times g$ for 5 $\min$. The supernatants were then dried under nitrogen, resuspended in $50 \mu \mathrm{l}$ ethanol, and a $25-\mu \mathrm{l}$ aliquot was analysed on a Hewlett-Packard 1090 HPLC system using a
Microsorb-MV C18 column (5 $\mu \mathrm{m} ; 4.6 \mathrm{~mm} \times 25 \mathrm{~cm}$; Rainin, Woburn, MA, USA) and a UV diode array detector (model 1040; Hewlett Packard). Methanol was used as the solvent at a flow rate of $2 \mathrm{ml} / \mathrm{min}$. Components were monitored at $290 \mathrm{~nm}$, and the calculations used were based on peak areas and the relative intensities determined using mixtures of authentic standards. The between-run CV was $2.8 \%$ for $\alpha$-tocopherol.

The soluble adhesion molecules ICAM-1 and E-selectin were measured by an enzyme immunoassay (R\&D Systems, Minneapolis, MN, USA), according to the manufacturer's instructions. These assays are calibrated against a purified soluble form of recombinant human adhesion molecule and they are specific for the adhesion molecule being measured, showing no cross-reactivity. The intraassay CV ranged from $3.3 \%$ to $5.6 \%$ and the interassay $\mathrm{CV}$ ranged from $5.6 \%$ to $10.2 \%$. The sensitivity of the assay is typically $<0.1 \mathrm{ng} / \mathrm{ml}$ for E-selectin and $<0.35 \mathrm{ng} /$ $\mathrm{ml}$ for ICAM-1. Lipoprotein subclass profiles were measured in freshly thawed frozen plasma samples by a proton NMR spectroscopic assay (LipoScience, Raleigh, NC, USA) [31]. The NMR method uses the characteristic signals produced by VLDL, LDL and HDL subclasses of different size as the basis for their quantification. Levels of large HDL (8.8-13 nm) and intermediate HDL (8.2-8.8 $\mathrm{nm})$ subclasses are expressed in lipid mass concentration units ( $\mathrm{mmol} / \mathrm{l}$ cholesterol), and total VLDL particle number is expressed in units of nanomoles per liter [31].

Serum and urinary albumin were measured by immunonephelometry [32, 33], and creatinine was assayed using an Ectachem 400 Analyzer (Eastman Kodak, Rochester, NY, USA) which, unlike picric acid-based methods, does not overestimate creatinine concentrations in diabetic individuals [34]. Overt nephropathy was defined as an AER $>200 \mu \mathrm{g} / \mathrm{min}$ in two of three timed urine collections or, in the absence of urine, a serum creatinine level $>153 \mu \mathrm{mol} / 1$, renal failure or renal transplantation.

\section{Statistical analyses}

Variables that did not follow a normal distribution were logarithmically transformed (i.e., triglyceride concentration, AER, C-reactive protein, homocysteine, $\alpha$-tocopherol, E-selectin and ICAM-1). The Student's $t$ test and the chi-square test were used to examine univariate associations between risk factors and incident CAD cases compared with control subjects, while Pearson correlations were used to examine the associations between risk factors and adiponectin concentration. Because higher levels of adiponectin have been previously reported among females $[4,11]$ and in macroalbuminuria [12], correlation coefficients were also estimated adjusting for gender and $\log _{10}$ AER. Unfortunately, we did not have adequate power to perform conditional logistic regression taking matching into account. Thus, we conducted Cox proportional hazards models with diabetes duration used as the time axis. The models included matching variables and baseline variables that have been previously demonstrated to be 
potentially important predictors of CAD (lipid levels and AER), or those that were found to be significantly different on univariate analysis. We also included age at onset of diabetes as a covariate, which effectively represents age in these models as diabetes duration is used as the time axis. Thus, the base model (model 1) included age at onset of diabetes, sex, $\log _{10}$ AER, HDL and non-HDL cholesterol. Model 2 included the variables in model 1 plus adiponectin concentration, whereas subsequent models allowed for individual inflammation markers. Time-dependent variables were constructed when the proportional hazards assumptions were not satisfied at $\alpha=0.05$ (i.e., age at diabetes onset and fibrinogen). However, it should be stated that the power of this test to detect departure from proportional hazards is low with small sample sizes. Since macroalbuminuria [12] and male sex [4, 11] have previously been shown to be associated with both cardiovascular disease and hypoadiponectinaemia, effect modification by sex and $\log _{10}$ AER was evaluated to examine whether the effect of adiponectin on CAD risk was different for these two groups. Measurements of lipoprotein subclasses (i.e., large and intermediate HDL subclass levels and VLDL particle number) determined by nuclear magnetic resonance spectroscopy [35], and cellular adhesion molecules (i.e., ICAM-1 and E-selectin [36] and $\alpha$-tocopherol [37]), have previously indicated that these molecules may play a role in the development of CAD in type 1 diabetes. We therefore also constructed models to evaluate whether the potential effect of adiponectin is independent of lipoprotein subclasses, soluble cellular adhesion molecules and antioxidants. All analyses were repeated replacing $\log _{10}$ AER with a dichotomous variable for the presence or absence of overt nephropathy.

Data were analysed using the SAS statistical package, version 8.0 (SAS Institute, Cary, NC, USA). All hazard ratios (HR) are reported per increase of $1 \mathrm{SD}$, and a $p$ value of $<0.05$ was considered significant.

\section{Results}

The demographic, anthropometric and clinical characteristics of the CAD cases and control subjects are presented in Table 1. Compared with the control subjects, total cholesterol, LDL cholesterol, non-HDL cholesterol, $\log _{10}$ triglycerides, fibrinogen, and white blood cell count were elevated among CAD cases. Moreover, a greater proportion of participants who developed CAD presented with increased urinary albumin excretion. In contrast, control subjects had borderline higher levels of HDL cholesterol and adiponectin compared with cases. Regardless of CAD status, adiponectin levels were higher in women than in men $(20.8$ vs. $16.5 \mu \mathrm{g} / \mathrm{ml}, p=0.009)$ and, surprisingly, in those with macroalbuminuria than in those without (21.3 $\mu \mathrm{g} / \mathrm{ml}$ vs. $17.4 \mu \mathrm{g} / \mathrm{ml}, p=0.04)$.

Table 2 presents Pearson correlation coefficients between adiponectin and other CAD risk factors, and correlations adjusted for sex and the $\log _{10}$ of AER. The
Table 1 Baseline characteristics of participants selected from the EDC by CAD status at the follow-up examination

Values shown are means \pm SD or percentages $(n)$ ${ }^{a}$ Logarithmically transformed before statistical testing

\begin{tabular}{|c|c|c|c|}
\hline Characteristic & Cases $(n=28)$ & Control subjects $(n=34)$ & $p$ value \\
\hline Age (years) & $34.5 \pm 7.6$ & $34.0 \pm 6.4$ & 0.78 \\
\hline Age at diabetes onset (years) & $6.9 \pm 4.4$ & $7.9 \pm 3.7$ & 0.35 \\
\hline Diabetes duration (years) & $27.6 \pm 8.2$ & $26.1 \pm 8.1$ & 0.48 \\
\hline $\operatorname{Men}(n)$ & $50.0(14)$ & $61.8(21)$ & 0.36 \\
\hline BMI $\left(\mathrm{kg} / \mathrm{m}^{2}\right)$ & $24.8 \pm 3.7$ & $24.1 \pm 2.9$ & 0.42 \\
\hline WHR & $0.8 \pm 0.09$ & $0.8 \pm 0.08$ & 0.41 \\
\hline Ever smokers $(n)$ & $50.0(14)$ & $35.3(12)$ & 0.25 \\
\hline $\mathrm{HbA}_{1}(\%)$ & $10.7 \pm 1.6$ & $10.2 \pm 1.31$ & 0.13 \\
\hline Systolic BP (mm Hg) & $119.0 \pm 15.7$ & $122.8 \pm 23.3$ & 0.45 \\
\hline Percent hypertensive $(n)$ & $25.0(7)$ & $29.4(10)$ & 0.70 \\
\hline Cholesterol $(\mathrm{mmol} / \mathrm{l})$ & $5.5 \pm 1.2$ & $4.7 \pm 0.8$ & 0.005 \\
\hline HDL cholesterol (mmol/l) & $1.3 \pm 0.2$ & $1.4 \pm 0.4$ & 0.05 \\
\hline LDL cholesterol (mmol/l) & $3.6 \pm 1.0$ & $2.9 \pm 0.8$ & 0.002 \\
\hline Non-HDL cholesterol (mmol/l) & $4.2 \pm 1.2$ & $3.4 \pm 0.8$ & 0.0009 \\
\hline Triglycerides $(\mathrm{mmol} / \mathrm{l})^{\mathrm{a}}$ & $1.3 \pm 0.9$ & $0.9 \pm 0.4$ & 0.02 \\
\hline Fibrinogen $(\mu \mathrm{mol} / \mathrm{l})$ & $9.9 \pm 3.2$ & $8.2 \pm 2.4$ & 0.02 \\
\hline Homocysteine $(\mu \mathrm{mol} / 1)$ & $9.3 \pm 3.0$ & $10.8 \pm 3.4$ & 0.07 \\
\hline C-reactive protein $(\mu \mathrm{g} / \mathrm{ml})^{\mathrm{a}}$ & $2.0 \pm 1.6$ & $2.1 \pm 2.9$ & 0.40 \\
\hline $\mathrm{eGDR}\left(\mathrm{mg} \mathrm{kg}^{-1} \min ^{-1}\right)$ & $6.9 \pm 2.0$ & $7.6 \pm 2.4$ & 0.20 \\
\hline $\mathrm{WBC} \times 10^{3} / \mathrm{mm}^{2}$ & $7.9 \pm 2.2$ & $6.8 \pm 1.4$ & 0.03 \\
\hline Beck Depression Inventory & $10.5 \pm 8.8$ & $7.4 \pm 6.9$ & 0.13 \\
\hline Adiponectin $(\mu \mathrm{g} / \mathrm{ml})$ & $16.4 \pm 4.5$ & $19.5 \pm 7.3$ & 0.047 \\
\hline $\operatorname{AER}(\mu \mathrm{g} / \mathrm{min})^{\mathrm{a}}$ & $909.7 \pm 1410.7$ & $248.0 \pm 1031.7$ & 0.003 \\
\hline \multicolumn{4}{|l|}{ Overt nephropathy } \\
\hline No & $64.3(18)$ & $85.3(29)$ & \\
\hline Yes & $35.7(10)$ & $14.7(5)$ & 0.06 \\
\hline
\end{tabular}


Table 2 Pearson correlation coefficients between adiponectin and other CAD risk factors
${ }^{\text {aP }}$ artial correlations, adjusting for sex and $\log _{10}$ AER (in the case of $\log _{10}$ AER, adjustment was performed only for sex)

\begin{tabular}{|c|c|c|c|c|}
\hline \multirow[t]{2}{*}{ CAD risk factor } & \multicolumn{4}{|c|}{ Adiponectin $(\mu \mathrm{g} / \mathrm{ml})$} \\
\hline & Unadjusted & $p$ value & Adjusted $^{\mathrm{a}}$ & $p$ value \\
\hline Age (years) & 0.25 & 0.05 & 0.29 & 0.02 \\
\hline Duration (years) & 0.15 & 0.25 & 0.18 & 0.17 \\
\hline BMI $\left(\mathrm{kg} / \mathrm{m}^{2}\right)$ & -0.23 & 0.07 & -0.22 & 0.10 \\
\hline WHR & -0.37 & 0.003 & -0.25 & 0.05 \\
\hline $\mathrm{HbA}_{1} \mathrm{c}(\%)$ & -0.09 & 0.47 & -0.19 & 0.15 \\
\hline eGDR (mg kg $\left.{ }^{-1} \min ^{-1}\right)$ & 0.14 & 0.28 & 0.21 & 0.12 \\
\hline Systolic BP (mm Hg) & 0.11 & 0.38 & 0.13 & 0.32 \\
\hline Cholesterol (mmol/l) & 0.02 & 0.85 & -0.10 & 0.44 \\
\hline HDL cholesterol (mmol/l) & 0.49 & $<0.0001$ & 0.51 & $<0.0001$ \\
\hline HDL cholesterol/ApoA1 & 0.31 & 0.02 & 0.30 & 0.02 \\
\hline LDL cholesterol (mmol/l) & 0.02 & 0.86 & -0.09 & 0.52 \\
\hline Non-HDL cholesterol (mmol/l) & -0.12 & 0.35 & -0.24 & 0.06 \\
\hline $\log _{10}$ triglycerides $(\mathrm{mmol} / \mathrm{l})$ & -0.33 & 0.009 & -0.45 & 0.0005 \\
\hline Fibrinogen $(\mathrm{mmol} / \mathrm{l})$ & -0.02 & 0.86 & -0.23 & 0.09 \\
\hline $\log _{10}$ homocysteine $(\mu \mathrm{mol} / 1)$ & 0.24 & 0.07 & 0.29 & 0.03 \\
\hline $\log _{10}$ C-reactive protein $(\mu \mathrm{g} / \mathrm{ml})$ & -0.12 & 0.38 & -0.18 & 0.18 \\
\hline $\mathrm{WBC} \times 10^{3} / \mathrm{mm}^{2}$ & -0.004 & 0.97 & -0.15 & 0.25 \\
\hline Beck Depression Inventory & -0.009 & 0.95 & -0.03 & 0.81 \\
\hline $\log _{10} \operatorname{AER}(\mu \mathrm{g} / \mathrm{min})$ & 0.18 & 0.16 & 0.25 & 0.05 \\
\hline $\log _{10} \alpha$-tocopherol $(\mu \mathrm{mol} / 1)$ & 0.11 & 0.41 & 0.004 & 0.98 \\
\hline $\log _{10} \operatorname{ICAM}-1(\mathrm{ng} / \mathrm{ml})$ & -0.15 & 0.26 & -0.18 & 0.21 \\
\hline $\log _{10}$ E-selectin $(\mathrm{ng} / \mathrm{ml})$ & -0.22 & 0.10 & -0.31 & 0.03 \\
\hline VLDL particle number $(\mathrm{nmol} / \mathrm{l})$ & -0.12 & 0.36 & -0.26 & 0.05 \\
\hline Large HDL (H45) (mmol/1 cholesterol) & 0.47 & 0.0002 & 0.49 & 0.0002 \\
\hline Intermediate HDL (H3) (mmol/1 cholesterol) & -0.14 & 0.30 & -0.18 & 0.19 \\
\hline
\end{tabular}

simple and adjusted correlations generally showed the same trends; however, the strength of the association was subject to variation. Serum adiponectin was positively correlated with HDL cholesterol $(p<0.0001)$ and large HDL $(p=0.0002)$, and inversely correlated with WHR $(p=0.003)$ and the $\log _{10}$ of triglycerides $(p=0.009)$. After adjusting for sex and the $\log _{10}$ of AER, an inverse association was observed between serum adiponectin and
E-selectin $(p=0.03)$, whereas positive correlations were shown between serum adiponectin and age $(p=0.02)$ and homocysteine $(p=0.03)$.

In multivariate analyses (Table 3), consistent significant predictors of CAD included age at diabetes onset, $\log _{10}$ AER, and adiponectin concentration. The effect of adiponectin remained when markers of inflammation were included in the models (models 3-5). When analyses were

Table 3 Cox proportional hazards models for the prediction of CAD

\begin{tabular}{|c|c|c|c|c|c|c|}
\hline Variable & SD & Model 1 & Model 2 & Model 3 & Model 4 & Model 5 \\
\hline Age at onset (years) ${ }^{\mathrm{a}}$ & 4.06 & $1.03(1.01-1.05)$ & $1.04(1.02-1.06)$ & $1.03(1.02-1.05)$ & $1.04(1.02-1.06)$ & $1.04(1.02-1.06)$ \\
\hline Sex & & $2.39(1.02-5.61)$ & $3.78(1.54-9.27)$ & $2.36(0.89-6.27)$ & $2.59(0.97-6.91)$ & $4.85(1.73-13.60)$ \\
\hline $\operatorname{AER}(\mu \mathrm{g} / \min )^{\mathrm{b}}$ & 2.40 & $1.31(0.82-2.09)$ & $2.03(1.13-3.65)$ & $2.29(1.26-4.19)$ & $1.82(0.99-3.34)$ & $2.35(1.26-4.37)$ \\
\hline HDL cholesterol (mmol/l) & 13.17 & $0.62(0.38-1.02)$ & $0.95(0.55-1.63)$ & $1.36(0.70-2.62)$ & $1.20(0.68-2.14)$ & $1.04(0.52-2.10)$ \\
\hline Non-HDL cholesterol (mmol/l) & 45.47 & $1.37(0.85-2.22)$ & $1.17(0.67-2.05)$ & $1.21(0.70-2.09)$ & $1.09(0.63-1.90)$ & $1.31(0.74-2.29)$ \\
\hline Adiponectin $(\mu \mathrm{g} / \mathrm{ml})$ & 6.32 & $\mathrm{~N} / \mathrm{A}$ & $0.37(0.19-0.73)$ & $0.30(0.14-0.63)$ & $0.38(0.19-0.76)$ & $0.37(0.18-0.79)$ \\
\hline $\mathrm{WBC} \times 10^{3} / \mathrm{mm}^{2}$ & 2.15 & N/A & N/A & $1.77(1.03-3.03)$ & N/A & $\mathrm{N} / \mathrm{A}$ \\
\hline Fibrinogen $(\mathrm{mmol} / \mathrm{l})^{\mathrm{a}}$ & 105.36 & N/A & N/A & $\mathrm{N} / \mathrm{A}$ & $1.02(1.003-1.04)$ & N/A \\
\hline Homocysteine $(\mu \mathrm{mol} / \mathrm{l})^{\mathrm{b}}$ & 0.30 & N/A & $\mathrm{N} / \mathrm{A}$ & N/A & N/A & $0.71(0.48-1.06)$ \\
\hline$-2 \mathrm{LL}$ & & 162.096 & 152.607 & 148.156 & 147.557 & 127.228 \\
\hline AIC & & 172.096 & 164.607 & 162.156 & 161.557 & 141.228 \\
\hline
\end{tabular}

Participants were identified from the EDC ( $n=62 ; 28$ cases, 34 controls). Values shown are hazard ratios $(95 \% \mathrm{CI})$ unless otherwise indicated. All hazard ratios are per $1 \mathrm{SD}$ increase

AIC Akaike's Information Criterion, $-2 L L-2 \log$ likelihood, $N / A$ variable not made available to model

${ }^{\text {a }}$ Time-dependent variable

${ }^{\mathrm{b}}$ Logarithmically transformed 
repeated, adding separately each of the two measured cellular adhesion molecules (E-selectin and ICAM-1), lipoprotein subclasses (large and intermediate HDL, VLDL particle number), or serum antioxidant $\alpha$-tocopherol, the association obtained between adiponectin concentration and $\mathrm{CAD}$ incidence did not materially change $(\mathrm{HR}=0.15$ for adiponectin with the addition of VLDL particle size and $\mathrm{HR}=0.23$ for adiponectin when any of the other novel predictors were included), despite the reduction in sample size due to the limited number of participants with information on all these covariates $(n=52)$. Substituting overt nephropathy status for $\log _{10}$ AER did not alter the findings of any of the analyses. We also examined other established CAD risk factors (hypertension, smoking and WHR), as well as BMI, $\mathrm{HbA}_{1}$, eGDR and C-reactive protein. However, their inclusion in the models did not significantly affect the results (data not shown). Interestingly, although homocysteine levels did not predict CAD in this cohort, the protective effect of adiponectin was confined to individuals with homocysteine levels above the median $(\geq 9.65 \mu \mathrm{mol} / \mathrm{l})$ concentration $(\mathrm{HR}=0.04,95 \%$ CI $0.002-0.68$ ), and a $p$ value of 0.02 was obtained for an interaction term between adiponectin and homocysteine. No significant effect modification was observed between adiponectin and sex $(p=0.38)$ or $\log _{10} \operatorname{AER}(p=0.39)$.

\section{Discussion}

In this cohort of subjects with type 1 diabetes, a decreased serum concentration of adiponectin was associated with an increased risk of CAD. Interestingly, this effect was independent of conventional risk factors and markers of inflammation and insulin resistance. Furthermore, the introduction of lipoprotein subclasses, cellular adhesion molecules or serum antioxidants to the prediction models did not alter the observed association. These findings suggest that adiponectin potentially possesses properties in addition to its anti-inflammatory effects.

In humans, low circulating levels of adiponectin have been associated with severity of insulin resistance, glucose intolerance and CAD [2, 10, 11]. Moreover, the plasma concentration of the protein increases with weight loss (a reduction in adipose tissue), suggesting that its production is inhibited via a negative feedback mechanism in obesity $[11,38]$. A recent report from Germany noted that a polymorphism in the adiponectin gene may increase the risk of obesity and, subsequently, insulin resistance among individuals without a familial predisposition to type 2 diabetes, whereas the effect of the polymorphism may be negligible in persons already burdened with other genetic factors [16]. Other data have suggested that physiologic concentrations of fasting plasma adiponectin may be involved in regulating tyrosine phosphorylation of the insulin receptor in skeletal muscle, and that low plasma adiponectin precedes a decrease in insulin sensitivity [39]. A recent nested case-control study provided the first prospective evidence that an increased adiponectin concentration is associated with a lower risk of subsequent type 2 diabetes after adjustment for traditional risk factors (70\% reduction in risk between the fourth and first quartile) [40].

Despite the abundance of studies on adiponectin concentration among cohorts of patients with type 2 diabetes or healthy individuals, we are only aware of two studies on the levels of this protein in type 1 diabetes. Consistent with our findings, Imagawa et al. [41] observed markedly higher adiponectin levels among adult individuals with a short duration (approximately 3 years) of type 1 diabetes (13.6 $\mu \mathrm{g} / \mathrm{ml}$ in males and $16.1 \mu \mathrm{g} / \mathrm{ml}$ in females) compared with BMI-matched healthy control subjects $(6.9 \mu \mathrm{g} / \mathrm{ml}$ in males and $10.0 \mu \mathrm{g} / \mathrm{ml}$ in females; $p<0.01)$. Perseghin et al. [42] also found that adiponectin levels were higher in insulinresistant patients with type 1 diabetes $(25 \mu \mathrm{g} / \mathrm{ml})$ than in healthy individuals $(16 \mu \mathrm{g} / \mathrm{ml}, p=0.05)$, persons with type 2 diabetes $(7 \mu \mathrm{g} / \mathrm{ml}, p=0.01)$, and nondiabetic, insulinresistant offspring of parents with type 2 diabetes (11 $\mu \mathrm{g} / \mathrm{ml}, p=0.03)$. Similarly, in the EDC cohort, the mean serum adiponectin concentration was $18.1 \pm 6.3 \mu \mathrm{g} / \mathrm{ml}$, which is higher than the concentrations previously reported among healthy adults $[10,11,43]$ and persons with type 2 diabetes $[10,11,42]$. The mechanisms responsible for this significant elevation in adiponectin concentration among patients with type 1 diabetes are yet to be fully elucidated. As insulin is the only hormone currently implicated in the regulation of adiponectin expression [44], this raises the possibility that the relatively high systemic levels of insulin in type 1 diabetes may play a role. Furthermore, chronic exposure of 3T3-L1 adipocytes to insulin was shown to suppress the expression of the adiponectin gene: insulin reduced levels of adiponectin mRNA in a dose- and timedependent manner [45]. Individuals with type 2 diabetes, obese persons, and healthy lean subjects undergoing a hyperinsulinaemic-euglycaemic glucose clamp have also been found to possess reduced concentrations of adiponectin [46]. However, in the study of Imagawa et al., insulin replacement therapy did not affect adiponectin concentration in a subgroup of seven patients with type 1 diabetes [41].

As previously reported $[2,11,43]$, low circulating adiponectin levels were associated with male sex in the EDC cohort. Androgens reduce plasma adiponectin, explaining the lower plasma protein levels observed among men, as well as some of the increased risk of insulin resistance and atherosclerosis in these individuals, compared with women [47]. Surprisingly, adiponectin levels were elevated among individuals with macroalbuminuria compared with those with normal albumin excretion. Similar findings were reported among Pima Indians with type 2 diabetes, even after adjustment for age, gender, diabetes duration and BMI [48]. Adiponectin levels have also been reported to be higher in dialysis patients $(15.0 \mu \mathrm{g} / \mathrm{ml})$ than in healthy control subjects $(6.3 \mu \mathrm{g} / \mathrm{ml}, p<0.0001)$ [12]. Although further studies are needed to replicate these findings, it has been suggested that changes in clearance rates may lead to an elevated adiponectin concentration in renal disease [49]. 
In contrast, Koshimura et al. [50] demonstrated that, although serum levels of adiponectin were increased in subjects with type 2 diabetes and overt nephropathy, urinary excretion levels were also markedly increased in these individuals. As the authors of this study propose, these results raise the possibility that adiponectin levels are raised in response to the microvascular damage that occurs in diabetic nephropathy. Homocysteine concentration also increases with worsening of glomerular filtration [51], and our observation of a greater effect of adiponectin among individuals with elevated homocysteine levels may indicate a greater effect among individuals with renal disease. However, no significant effect modification was observed between adiponectin and $\log _{10}$ AER or, in separate analyses, nephropathy status. It is therefore intriguing to speculate whether raised adiponectin levels in renal disease have the same, or perhaps greater, protective effects. If this proves to be the case, despite the higher risk of CAD and higher overall adiponectin concentration, this would argue for a direct effect, while if the "relative" protection is lost, an indirect marker role would be more likely.

Our data suggest that a direct effect is likely, for even among individuals with type 1 diabetes, who also seem to exhibit increased concentrations of serum adiponectin, an inverse association was observed between adiponectin levels and the incidence of CAD. There was a remarkable $63 \%$ reduction in risk of CAD per $6.3 \mu \mathrm{g} / \mathrm{ml}$ increase in serum adiponectin levels after controlling for urinary albumin excretion. These results are striking, despite the relatively small number of cases and controls, the major weakness of the present study. While these results need to be confirmed in a larger sample, it should be noted that the subset of cases for whom serum samples were available did not vary substantially from the total group of cases with respect to either risk factor profile or type of CAD. Furthermore, power analyses suggested that we had $80 \%$ power to detect a $3 \mu \mathrm{g} / \mathrm{ml}$ difference in adiponectin concentration between cases and control subjects (similar differences between individuals with and without CAD have been reported by Hotta et al. [11] in diabetes), given a standard deviation of $6.32 \mu \mathrm{g} / \mathrm{ml}$ and $\alpha=0.05$. Another limitation of this report is that, due to the small sample size, paired data were analysed as if they were unpaired. However, this limitation does not negate the findings, as it would tend to lead to a bias toward the null. In addition, matching variables were adjusted for in all models.

In conclusion, our results raise the possibility that adiponectin may prove to be a useful marker of cardiovascular risk and a potential therapeutic target for cardiovascular risk prevention, especially in subgroups of the high-risk population. However, the increased levels of adiponectin observed in persons with type 1 diabetes and in renal disease appear contradictory to the elevated risk of cardiovascular disease in these states and thus merit further study.
Acknowledgements This research was supported by NIH grant number DK34818. James Otvos is employed by, is a stockholder of, and serves on the board of directors of LipoScience, a diagnostic laboratory company that performed the lipoprotein subclass analyses described in this paper.

\section{References}

1. Maeda K, Okubo K, Shimomura I, Funahashi T, Matsuzawa Y, Matsubara K (1996) cDNA cloning and expression of a novel adipose specific collagen-like factor, apM1 (AdiPose Most abundant Gene transcript 1). Biochem Biophys Res Commun 221:286-289

2. Arita Y, Kihara S, Ouchi N et al (1999) Paradoxical decrease of an adipose-specific protein, adiponectin, in obesity. Biochem Biophys Res Commun 257:79-83

3. Okamoto Y, Arita Y, Nishida M et al (2000) An adipocytederived plasma protein, adiponectin, adheres to injured vascular walls. Horm Metab Res 32:47-50

4. Ouchi N, Kihara S, Arita Y et al (1999) Novel modulator for endothelial adhesion molecules: adipocyte-derived plasma protein, adiponectin. Circulation 100:2473-2476

5. Yokota, T, Oritani K, Takahashi I et al (2000) Adiponectin, a new member of the family of soluble defense collagens, negatively regulates the growth of myelomonocytic progenitors and the functions of macrophages. Blood 96:1723-1732

6. Takahashi M, Arita Y, Yamagata K et al (2000) Genomic structure and mutations in adipose-specific gene, adiponectin. Int J Obes Relat Metab Disord 24:861-868

7. Yamauchi T, Kamon J, Waki $\mathrm{H}$ et al (2001) The fat-derived hormone adiponectin reverses insulin resistance associated with both lipoatrophy and obesity. Nat Med 7:941-946

8. Kubota N, Terauchi Y, Yamauchi T et al (2002) Disruption of adiponectin causes insulin resistance and neointimal formation. J Biol Chem 277:25863-25866

9. Matsuda M, Shimomura I, Sata M et al (2002) Role of adiponectin in preventing vascular stenosis. J Biol Chem 277:37487-37491

10. Weyer C, Funahashi T, Tanaka S et al (2001) Hypoadiponectinemia in obesity and type 2 diabetes: close association with insulin resistance and hyperinsulinemia. J Clin Endocrinol Metab 86:1930-1935

11. Hotta K, Funahashi T, Arita Y et al (2000) Plasma concentrations of a novel, adipose-specific protein, adiponectin, in type 2 diabetic patients. Arterioscler Thromb Vasc Biol 20:1595-1599

12. Zoccali C, Mallamaci F, Tripepi G et al (2002) Adiponectin, metabolic risk factors, and cardiovascular events among patients with end-stage renal disease. J Am Soc Nephrol 13:134 141

13. Orchard TJ, Olson JC, Erbey JR et al (2003) Insulin resistancerelated factors, but not glycemia, predict coronary artery disease in type 1 diabetes: 10-year follow-up data from the Pittsburgh Epidemiology of Diabetes Complications Study. Diabetes Care 26:1374-1379

14. Hara K, Boutin P, Mori Y et al (2002) Genetic variation in the gene encoding adiponectin is associated with an increased risk of type 2 diabetes in the Japanese population. Diabetes 51:536540

15. Kondo H, Shimomura I, Matsukawa Y et al (2002) Association of adiponectin mutation with type 2 diabetes. A candidate gene for the insulin resistance syndrome. Diabetes 51:2325-2328

16. Stumvoll M, Tschritter O, Frutschhe A et al (2002) Association of the T-G polymorphism in adiponectin (Exon 2) with obesity and insulin sensitivity. Diabetes 51:37-41

17. Orchard TJ, Dorman JS, Maser RE et al (1990) Prevalence of complications of IDDM by sex and duration: Pittsburgh Epidemiology of Diabetes Complications Study II. Diabetes 39:741-747 
18. Orchard TJ, Dorman JS, Maser RE et al (1990) Factors associated with avoidance of severe complications after $25 \mathrm{yr}$ of IDDM: Pittsburgh Epidemiology of Diabetes Complications Study-I. Diabetes Care 13:741-747

19. Wagener DK, Sacks JM, LaPorte RE, MacGregor JM (1982) The Pittsburgh study of insulin-dependent diabetes mellitus: risk for diabetes among relatives of IDDM. Diabetes 31:136144

20. Borhani NO, Kass EH, Langford HG, Payne GH, Remington RD, Stamler J (1976) The hypertension detection and follow-up program. Prev Med 5:207-215

21. Beck AT, Steer RA, Garbin MG (1988) Psychometric properties of the Beck Depression Inventory: twenty-five years of evaluation. Clin Psychol Rev 8:77-100

22. Warnick GR, Albers JJ (1978) Heparin- $\mathrm{Mn}^{2+}$ quantitation of high-density-lipoprotein cholesterol: an ultrafiltration procedure for lipemic samples. Clin Chem 24:900-904

23. National Institutes of Health, Department of Health (1975) Lipid research clinics program. US Government Printing Office, Washington, D.C., pp 75-628

24. Allain CC, Poon LS, Chan CSG, Richmond W, Fu PC (1974) Enzymatic determination of total serum cholesterol. Clin Chem 20:470-475

25. Bucolo G, David H (1973) Quantitative determination of serum triglycerides by the use of enzymes. Clin Chem 19:476-482

26. Friedewald WT, Levy RI, Fredrickson DS (1972) Estimation of the concentration of low-density lipoprotein cholesterol in plasma, without use of the preparative ultracentrifuge. Clin Chem 18:499-502

27. Williams KV, Erbey JR, Becker DJ, Arslanian S, Orchard TJ (2000) Can clinical factors estimate insulin resistance in type 1 diabetes? Diabetes 49:626-632

28. Macy E, Hayes T, Tracy R (1997) Variability in the measurement of C-reactive protein in health subjects: implication for reference interval and epidemiological applications. Clin Chem 43:52-58

29. Driskell WJ, Neese JW, Bryant CC, Bashor MM (1982) Measure of vitamin A and vitamin $\mathrm{E}$ in human serum by high performance liquid chromatography. J Chromatogr 231:439444

30. Miller KW, Lorr NA, Yang CS (1984) Simultaneous determination of plasma retinol, $\alpha$-tocopherol, lycopene, $\alpha$-carotene and $\beta$-carotene by high-performance liquid chromatography. Anal Biochem 138:340-345

31. Otvos JD (2002) Measurement of lipoprotein subclass profiles by nuclear magnetic resonance spectroscopy. Clin Lab 48:171180

32. Ellis D, Buffone GJ (1977) A new approach to the evaluation of proteinuric states. Clin Chem 23:666-670

33. Ellis D, Coonrod BA, Dorman JS et al (1989) Choice of urine sample predictive of microalbuminuria in patients with insulindependent diabetes mellitus. Am J Kidney Dis 4:321-328

34. Assadi FK, John EG, Fornell L, Rosenthal IM (1985) Falsely elevated serum creatinine concentration in ketoacidosis. J Pediatr 107:562-564

35. Soedamah-Muthu SS, Chang YF, Otvos J, Evans RW, Orchard TJ (2003) Lipoprotein subclass measurements by nuclear magnetic resonance spectroscopy improve the prediction of coronary artery disease in type 1 diabetes. A prospective report from the Pittsburgh Epidemiology of Diabetes Complications Study. Diabetologia 46:674-682
36. Costacou T, Zgibor JC, Walsh M, Lopes-Virella MF, Otvos J, Orchard TJ (2003) Why is E-selectin such a good predictor of coronary artery disease in type 1 diabetes? The Pittsburgh Epidemiology of Diabetes Complications Study. Circulation 108:3370 (Abstract)

37. Costacou T, Evans RW, Tyurina YY, Kagan VE, Orchard TJ (2004) Antioxidants and coronary artery disease among individuals with type 1 diabetes: findings from the Pittsburgh Epidemiology of Diabetes Complications (EDC) Study. In: Proceedings of the 39th annual meeting of the European Diabetes Epidemiology Group (EDEG): 44 (Abstract)

38. Yang WS, Lee WJ, Funahashi T et al (2001) Weight reduction increases plasma levels of an adipose-derived anti-inflammatory protein, adiponectin. J Clin Endocrinol Metab 86:38153819

39. Stefan N, Vozarova B, Funahashi T et al (2002) Plasma adiponectin concentration is associated with skeletal muscle insulin receptor tyrosine phosphorylation, and low plasma concentration precedes a decrease in whole-body insulin sensitivity in humans. Diabetes 51:1884-1888

40. Spranger J, Kroke A, Mohlig M et al (2003) Adiponectin and protection against type 2 diabetes mellitus. Lancet 361:226-228

41. Imagawa A, Funahashi T, Nakamura T et al (2002) Elevated serum concentration of adipose-derived factor, adiponectin, in patients with type 1 diabetes. Diabetes Care 25:1665-1666

42. Perseghin G, Lattuada G, Danna M et al (2003) Insulin resistance, intramyocellular lipid content, and plasma adiponectin in patients with type 1 diabetes. Am J Physiol Endocrinol Metab 285:E1174-E1181

43. Cnop M, Havel PJ, Utzschneider KM et al (2003) Relationship of adiponectin to body fat distribution, insulin sensitivity and plasma lipoproteins: evidence for independent roles of age and sex. Diabetologia 46:459-469

44. Scherer PE, Williams S, Fogliano M, Baldini G, Lodish HE (1995) A novel serum protein similar to C1q, produced exclusively in adipocytes. J Biol Chem 270:26746-26749

45. Fasshauer M, Klein J, Neumann S, Eszlinger M, Paschke R (2002) Hormonal regulation of adiponectin gene expression in 3T3-L1 adipocytes. Biochem Biophys Res Commun 290: 1084-1089

46. Yu JG, Javorschi S, Hevener AL et al (2002) The effect of thiazolidinediones on plasma adiponectin levels in normal, obese, and type 2 diabetic subjects. Diabetes 51:2968-2974

47. Nishizawa H, Shimomura I, Kishida K et al (2002) Androgens decrease plasma adiponectin, an insulin-sensitizing adipocytederived protein. Diabetes 51:2734-2741

48. Looker H, Funahashi T, Krakoff J et al (2003) Relationship between serum adiponectin levels and measures of renal function in type 2 diabetes. Diabetes 52 [Suppl 1]:41A (Abstract)

49. Diez JJ, Iglesias P (2003) The role of the novel adipocytederived hormone adiponectin in human disease. Eur J Endocrinol 148:293-300

50. Koshimura J, Fujita H, Narita T, Shimotomai T et al (2004) Urinary adiponectin excretion is increased in patients with overt diabetic nephropathy. Biochem Biophys Res Commun 316: 165-169

51. Emoto M, Kanda H, Shoji T et al (2001) Impact of insulin resistance and nephropathy on homocysteine in type 2 diabetes. Diabetes Care 24:533-538 